\title{
Elevation-dependent relationships between climate change and grassland vegetation variation across the Qinghai-Xizang Plateau
}

\author{
Jian Tao, ${ }^{\text {a,b }}$ Yangjian Zhang, ${ }^{\text {a* }}$ Jinwei Dong, ${ }^{c}$ Yu Fu, ${ }^{\mathrm{d}}$ Juntao Zhu, ${ }^{\mathrm{a}}$ Geli Zhang, ${ }^{\text {a,c }}$ Yanbin \\ Jiang, ${ }^{\mathrm{a}}$ Li Tian, ${ }^{\mathrm{a}}$ Xianzhou Zhang, ${ }^{\mathrm{a}}$ Tao Zhang, ${ }^{\mathrm{a}, \mathrm{b}}$ and Yi Xi ${ }^{\mathrm{a}, \mathrm{b}}$ \\ ${ }^{a}$ Lhasa Station, Key Laboratory of Ecosystem Network Observation and Modeling, Institute of Geographic Sciences and Natural Resources \\ Research, Chinese Academy of Sciences, Beijing, China \\ ${ }^{\mathrm{b}}$ University of Chinese Academy of Sciences, Beijing, China \\ ${ }^{c}$ Department of Microbiology and Plant Biology, Center for Spatial Analysis, University of Oklahoma, Norman, OK, USA \\ ${ }^{\mathrm{d}}$ College of Architecture and Urban Planning, Hunan University of Science and Technology, Xiangtan, China
}

\begin{abstract}
As one of the most sensitive regions to climate change, the Qinghai-Xizang Plateau has been widely investigated as one unity for impacts of climate change on alpine grassland. However, previous findings might be confounded by distinct climate sensitivities at different elevations and different regional climates between Qinghai Province and Xizang Province, which lie at the two sides of Tanggula Mountains. In this study, we explored change trends of grassland vegetation, temperature and precipitation in growing season from 1982 to 2011, and elevation-dependent effects of climate change on grassland vegetation in the two provinces separately. The plateau grassland greenness gained improvement under climate warming and wetting during the past 30 years, especially in Qinghai Province. Temperature increased significantly with a warming magnitude of more than $1.5^{\circ} \mathrm{C}$ over the plateau grassland. The interannual change of precipitation showed contrary trends between the two provinces. The main climate factor driving the grassland vegetation variation varied between the two provinces, with temperature being the main factor in Qinghai Province and precipitation being the main factor in Xizang Province. In particular, a more significant correlation between climate change and grassland vegetation variation was found at higher elevations, which reveals higher climate sensitivity in higher elevation areas of the plateau.
\end{abstract}

KEY WORDS climate change; grassland vegetation variation; elevational dependence; the Qinghai-Xizang Plateau

Received 16 December 2013; Revised 25 March 2014; Accepted 21 May 2014

\section{Introduction}

Climate change has brought widespread effects on global vegetation ecosystem (Walther et al., 2002; Parmesan and Yohe, 2003; Tao et al., 2013a). The effects are suggested to have strong spatial variability in regions that are sensitive to climate change (Myneni et al., 1997; Zhou et al., 2001; Gerten et al., 2004; Piao et al., 2006a; Piao et al., 2011a). Both instrumental observations and model simulations have tracked an enhanced recent climate change in high elevation mountains (Beniston et al., 1997; Giorgi et al., 1997; Pepin and Lundquist, 2008), such as the Qinghai-Xizang Plateau (Liu and Chen, 2000; Kang et al., 2010).

The Qinghai-Xizang Plateau, synonymous with the Tibetan Plateau, is the highest and largest plateau in the world. The plateau is assigned a crucial role in shaping Asian climate. The plateau exerts a powerful thermal influence on the Asian climate system (He et al., 1987;

\footnotetext{
* Correspondence to: Y. Zhang, Lhasa station, Key Laboratory of Ecosystem Network Observation and Modeling, Institute of Geographic Sciences and Natural Resources Research, Chinese Academy of Sciences, Beijing 100101, China. E-mail: zhangyj@igsnrr.ac.cn
}

Smith and Shi, 1992; Yanai and Li, 1994; Wu et al., 2012). The extensive plateau surface acts as a heating source to impact energy flux between land and atmosphere (Guo et al., 2011; Yang et al., 2011a; Zhu et al., 2012). The thermal influence is much stronger in the southern plateau than in the northern plateau because the largest heating source lies in the south of the plateau (Yanai and Li, 1994; Molnar et al., 2010).

On the other hand, the plateau is located at the northern and western periphery of the South Asian monsoon and the East Asian monsoon, respectively, and therefore acts as an obstacle to the Asian monsoon. The high terrains of the plateau not only affect the South Asian monsoon by preventing cold and dry extra-tropical atmosphere from convecting with warm and moist tropical air masses (Chou et al., 2001; Privé and Plumb, 2007; Boos and Emanuel, 2009), but also play an unnegligible role in influencing the East Asian monsoon by altering eastward westerly jet (Liang and Wang, 1998; Xie et al., 2006; Wu et al., 2007). Shaped by local topography, water vapour sources supplying to the plateau is divided into three routes, i.e. the Arabian Sea and Bay of Bengal, the South China Sea, and the mid-latitude westerly (Simmonds et al., 1999; Wang 


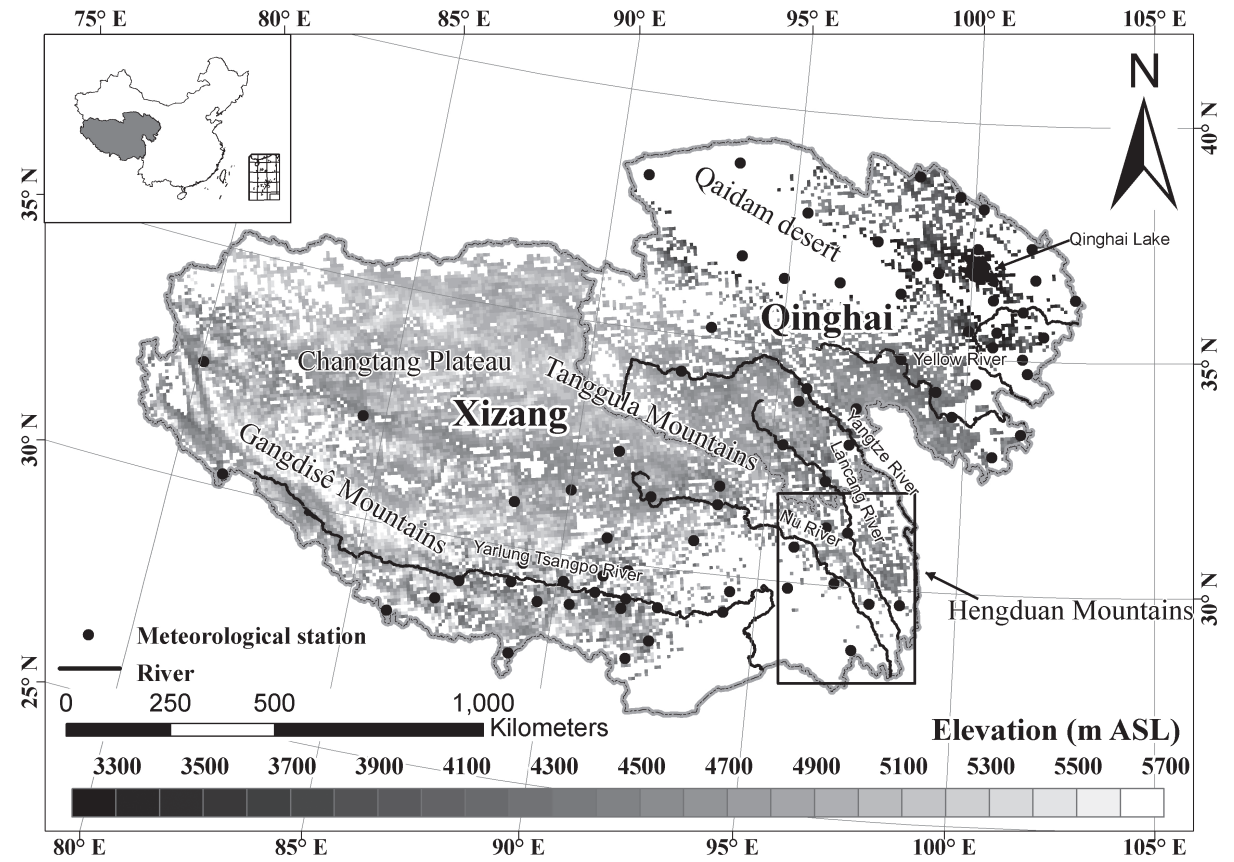

Figure 1. Map of the Qinghai-Xizang Plateau. Black dots denote locations of meteorological stations; solid lines denote rivers.

and Fan, 1999). The water vapour source of the South Asian monsoon originates from the Arabian Sea and Bay of Bengal, and dominates the summer precipitation over the southern plateau (Fu et al., 2006; Feng and Zhou, 2012; Yang et al., 2014a). For the East Asian monsoon, the water vapour transported from the South China Sea converges with the subtropical anticyclone from the West North Pacific in southern China, and then collocates with the mid-latitude westerly and turns northeastwards in the northeastern plateau (Chen et al., 2000; Zhao and Chen, 2001; Duan and Wu, 2005; Li et al., 2010; Wu et al., 2012).

A plenty of studies have investigated climate change in the plateau during the late half of the 20th century using ground meteorological records (Liu et al., 2006; You et al., 2008; Rangwala et al., 2009), remote sensing data (Qin et al., 2009; Tao et al., 2013b), climate model (Chen et al., 2003; Yang et al., 2011b; Yin et al., 2013), and reanalysis products (Frauenfeld et al., 2005; You et al., 2010; Feng and Zhou, 2012; Wang and Guo, 2012). The entire plateau has experienced an overall climate warming and wetting trend since the 1980s. However, such climate change showed evident spatial heterogeneity, with more obvious warming and wetting over the northern plateau (Yang et al., 2011b; Yin et al., 2013), especially at higher elevations (Liu et al., 2006; Arakawa and Kitoh, 2012; Rangwala and Miller, 2012). In contrast, precipitation decreased over the southeastern plateau (Liu et al., 2009a; Yang et al., 2014a). This contradictory precipitation trend is attributed to different water vapour sources, and different terrain and topography between the northern and the southern plateau (Chen et al., 2012; Wang and Guo, 2012; Yang et al., 2014a). Numerous studies further indicated that such contrast is more obvious between the two sides of the Tanggula Mountains (Zhang et al., 2004; Yang et al., 2006, 2007a; Liu et al., 2008).

The Tanggula Mountains divide the plateau into two unique and independent geographical units as Qinghai Province and Xizang Province in the northeastern and southwestern plateau, respectively (Figure 1). Regional atmospheric circulation is influenced by the existence of the mountains and consequently generating different climate characteristics between the two sides, especially for precipitation. In Qinghai province, water vapour is carried by the East Asian monsoon and mid-latitude westerly converge in the confluent region of the northeastern plateau (Chen et al., 2000; Xu et al., 2008; Wu et al., 2012). In Xizang Province, water vapour is carried by the South Asian monsoon through the middle Himalaya and the southeastern part of the province to the northwestern plateau (Yang et al., 2007b; Feng and Zhou, 2012; Wang and Guo, 2012). The southeastern Xizang Province is wet due to the vapour obstruction by the Tanggula Mountains. The northward water vapour carried by the South Asian monsoon can barely reach the north side of the Tanggula Mountains (Feng and Zhou, 2012; Wang and Guo, 2012).

The dramatic climate change has resulted in corresponding vegetation variation in the plateau based on region-scale remotely sensed analyses (Yang and Piao, 2006; Gao et al., 2010; Piao et al., 2011a; Cong et al., 2013; Shen et al., 2014) and model simulation (Yang et al., 2008; Zhong et al., 2010; Ni and Herzschuh, 2011; Zuo et al., 2011; Piao et al., 2012). The grassland vegetation response to climate change shows obvious elevational and spatial patterns. Using normalized difference vegetation index (NDVI), remotely sensed studies found enhanced grassland vegetation greenness in the plateau during 1982-2000, followed by grassland degradation 
and productivity reduction during 2000-2006 (Piao et al., 2006a; Gao et al., 2009; Gao et al., 2010). The degradation trend was more obvious in the northwestern high elevation plateau (Changtang Plateau). A widespread advanced phenological onset date and delayed phenological end date were also tracked by remote sensing data (Shen et al., 2011; Cong et al., 2013; Che etal., 2014; Shen et al., 2014). In particular, the phenological onset and end dates both occurred earlier along increasing elevations over the plateau. Model simulations revealed different driving factors on grassland net primary productivity (NPP) between the two provinces (Gao et al., 2009; Fan et al., 2010; Piao et al., 2012), with temperature being the main factor in Qinghai Province and precipitation being the main factor in Xizang Province.

Previous studies on climate change, vegetation activity and their relationships usually treated the plateau as one single unity. However, these studies could be confounded by elevational and regional climate heterogeneities, which can complicate vegetation response to climate change on the plateau (Chang, 1981; Tao et al., 2013b). Similar elevation-dependent responses of vegetation to climate have already been reported (Wang et al., 2007; Lu et al., 2008; Piao et al., 2011a; Shen et al., 2014). On the other hand, climate regime and its effects on grassland vegetation exhibit evident differences between Qinghai Province and Xizang Province. The above-mentioned confounding factors reveal that the response of the plateau grasslands to climate change needs to be further explored in a more spatially specific manner. In particular, Qinghai Province and Xizang Province need to be treated as separate units. To this end, we used a 30-year long-term NOAA/AVHRR NDVI dataset to examine vegetation response to climate change at each elevation bin by treating Qinghai Province and Xizang Province separately. Specifically, we addressed the following questions:

(1) How have the plateau grassland vegetation and climate changed during 1982-2011?

(2) How did the change trends of grassland vegetation, climate, and the relationships between them vary along the elevation bins and between the two provinces?

\section{Data and methods}

\subsection{Study area}

The Qinghai-Xizang Plateau, located in southwestern China, is known as 'the roof of the world' with an average elevation of more than $4000 \mathrm{~m}$ above sea level (ASL) (Figure 1). The plateau plays an important role as the headwater region of major rivers in Asia, and as habitats for endangered wildlives. Alpine grasslands, including alpine meadow and steppe, are the dominant vegetation type on the plateau (Editorial Board of Vegetation Map of China, 2001). The plateau is composed of two geographical units of Qinghai Province and Xizang Province with Tanggula Mountains in between. Between the two provinces, the topographical characteristics are different
(Figure 1). In Qinghai Province, the elevation grows higher from the northeastern foot to the same-side peak gradually and the elevation gradient is relatively simple. In Xizang Province, elevation increases from low to high along numerous mountains (e.g. Gangtise Mountains, Himalaya Mountains and the Changtang Plateau), forming several humps.

In the plateau, temperature is higher at low elevations of northeastern Qinghai Province and southeastern Xizang Province (Figure 2(a)). The warmest and coldest months are July and January, respectively. The averaged daily precipitation decreases from east to west in Qinghai Province and from southeast to northwest in Xizang Province, respectively (Figure 2(b)). The spatial climate gradients are different between the two provinces (Figure 2(c)). In Qinghai Province, the northern grasslands are located in the temperate zone, while southern grasslands are situated in the sub-arctic zone. The eastern and southeastern grasslands are fed by sub-humid/humid climate, but the northwestern grasslands feature a semi-arid/arid/extreme arid climate. In Xizang province, grasslands are mostly distributed in sub-arctic/arctic zone with semi-arid/arid climate. Accordingly, the growing season grassland NDVI (GSNDVI) decreases from east to west in Qinghai Province and from southeast to northwest in Xizang Province (Figure 2(c)). The highest grassland GSNDVI was observed in the warm and wet eastern Qinghai Province and southeastern Xizang Province, while the lowest grassland GSNDVI was detected in the northwestern Qinghai Province and the northern Xizang Province.

\subsection{Data}

The AVHRR NDVI dataset derived from the Global Inventory Modelling and Mapping Studies (GIMMS) was used in this study. This dataset is the longest running series of NDVI products suitable for large-scale ecological studies (Tucker et al., 2005). The earlier version of this dataset (i.e. GIMMS 1982-2006) has been intensively used in exploring the relationship between vegetation variation and climate change at regional scales (Nemani et al., 2003). To date, the third generation of the GIMMS (GIMMS3g) dataset, a new 30-year continuous series of NDVI dataset with a spatial resolution of $8 \mathrm{~km} \times 8 \mathrm{~km}$ and a temporal resolution of a half-month interval from 1982 to 2011 has been released. The dataset was produced with AVHRR sensors from NOAA 7 to 18 satellites and proved to be highly comparable with MODIS and SPOT data (Fensholt et al., 2009; Fensholt and Proud, 2012; Howard et al., 2012; Zhu et al., 2013), and has been used widely in China and the Qinghai-Xizang Plateau (Cong et al., 2013; Che et al., 2014; Shen et al., 2014). In this study, we only used grassland NDVI data in growing season, which is equal to the period from May to September (Piao et al., 2011a).

Climate data was derived from the China Meteorological Administration (CMA), which maintains 78 meteorological stations in the Qinghai-Xizang Plateau. We selected daily mean temperature and daily total precipitation records from 1982 to 2011 and aggregated them 

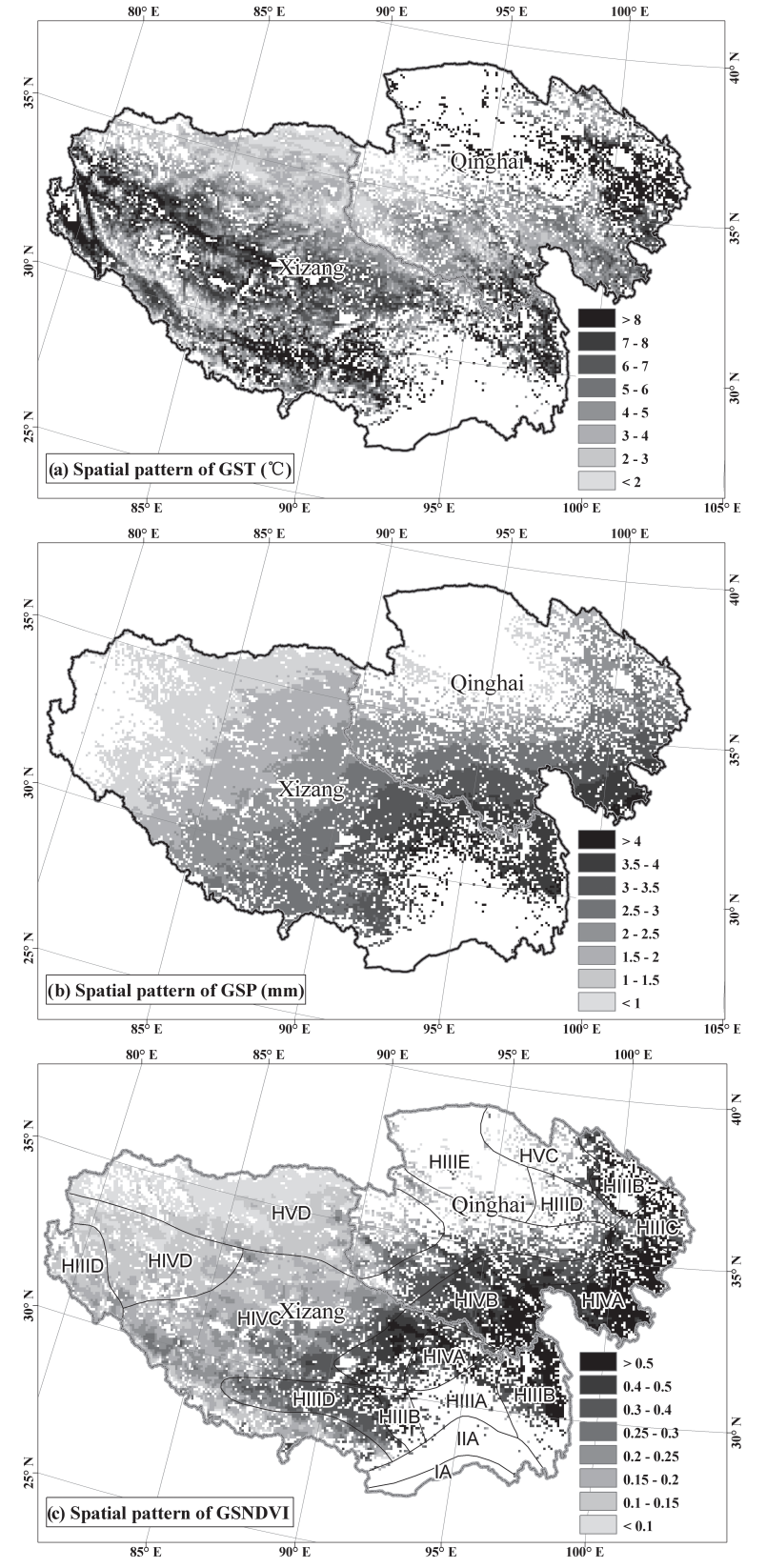

Figure 2. Spatial patterns of growing season temperature (GST) (a), growing season precipitation (GSP) (b), and growing season NDVI (GSNDVI) (c) of the plateau grassland. In panel (c), tropical (IA)/sub-tropical (IIA) humid climate, alpine temperate humid (HIIIA)/semi-humid (HIIIB)/semi-arid (HIIIC)/arid (HIIID)/extreme arid (HIIIE) climate, alpine sub-arctic humid (HIVA)/semi-humid (HIVB)/semi-arid (HIVC)/arid (HIVD) climate and alpine arctic semi-arid (HVC)/arid (HVD) climate.

to a half-month average to match the temporal resolution of the GIMMS3g NDVI dataset. The aggregated climate data were interpolated to spatially continuous ones and then re-aggregated to growing season average temperature (GST) and growing season average precipitation (GSP) with an $8 \mathrm{~km} \times 8 \mathrm{~km}$ spatial resolution. We used the thin-plate smoothing splines interpolation method of the ANUspline software (Hutchinson and Dowling, 1991). The ANUspline software has been proven to have a higher accuracy in mountain areas than other interpolation methods because it includes elevation as a covariate into the interpolation process (Hutchinson, 1995).

We used land cover data from the Data Center of Resources and Environmental Sciences, Chinese Academy of Sciences as the baseline map to define the grassland distribution (Liu et al., 2005; Dong et al., 2009). The Shuttle Radar Topography Mission (SRTM) digital elevation data with a $90 \mathrm{~m} \times 90 \mathrm{~m}$ spatial resolution were aggregated to an $8 \mathrm{~km} \times 8 \mathrm{~km}$ resolution to match other datasets. We took the mean values of GSNDVI, GST and GSP at each 100-m elevation bin during 1982-2011 to analyse the elevation-dependent climate change, vegetation variation and their relationships. To avoid anomalous fluctuation caused by inadequate pixels, we excluded elevation bins whose pixel amounts were less than 100, which resulted in elevation bins from 3200 to $5200 \mathrm{~m}$ ASL in Qinghai Province and from 4100 to $5700 \mathrm{~m}$ ASL in Xizang Province being included in this study (Figure 1). Pixels above $4500 \mathrm{~m}$ ASL occupy a much higher percentage in Xizang Province than in Qinghai Province.

\subsection{Methods}

We first calculated the change trends of GSNDVI, GST and GSP, and then computed the standardized regression coefficients between GSNDVI and GST, and GSP at each elevation bin in the two provinces separately. The change trends of GSNDVI, GST and GSP were defined as their linear regression slopes against time. We also divided the change trends of GSNDVI by an averaged GSNDVI value during 1982-2011 to calculate their change percentage at each elevation bin. Second, we calculated the standardized regression coefficients of GST and GSP to evaluate which has the main effect on GSNDVI variation by using a linear regression model (Bring, 1994):

$$
\frac{y-y_{\text {mean }}}{\mathrm{SD}_{y}}=a+b_{1} \frac{x_{1}-x_{1 \text { mean }}}{\mathrm{SD}_{x_{1}}}+b_{2} \frac{x_{2}-x_{2 \text { mean }}}{\mathrm{SD}_{x_{2}}}
$$

where $y$ is a value array of GSNDVI at an elevation bin during 1982-2011; $y_{\text {mean }}$, the mean value of $y ; \mathrm{SD}_{y}$, the standard deviation of $y ; x_{1}, x_{2}$ are the value arrays of GST and GSP at the same elevation bin as $y$ during 1982-2011; $x_{1 \text { mean }}, x_{2 \text { mean }}$ are the mean values of $x_{1}, x_{2} ; \mathrm{SD}_{x 1}, \mathrm{SD}_{x 2}$ are the standard deviations of $x_{1}, x_{2} ; a$, the intercept; and $b_{1}$, $b_{2}$ are the standardized regression coefficients.

\section{Results}

3.1. Interannual change of grassland GSNDVI, GST and GSP

The interannual change slopes of the spatially averaged grassland GSNDVI, GST and GSP on the whole plateau were positive during 1982-2011 (Figure 3). The grassland GSNDVI increased gradually from 1982 to 2000 (Qinghai Province: slope $=0.0011$ year $^{-1}, p<0.01, n=19$; Xizang Province: slope $=0.0008$ year $\left.^{-1}, p<0.001, n=19\right)$, and then shifted to decreasing from 2000 to 2006 (Qinghai Province: slope $=-0.0013$ year $^{-1}, p=0.53, n=7$; Xizang Province: slope $=-0.0020$ year $\left.^{-1}, p=0.02, n=7\right)$. After 


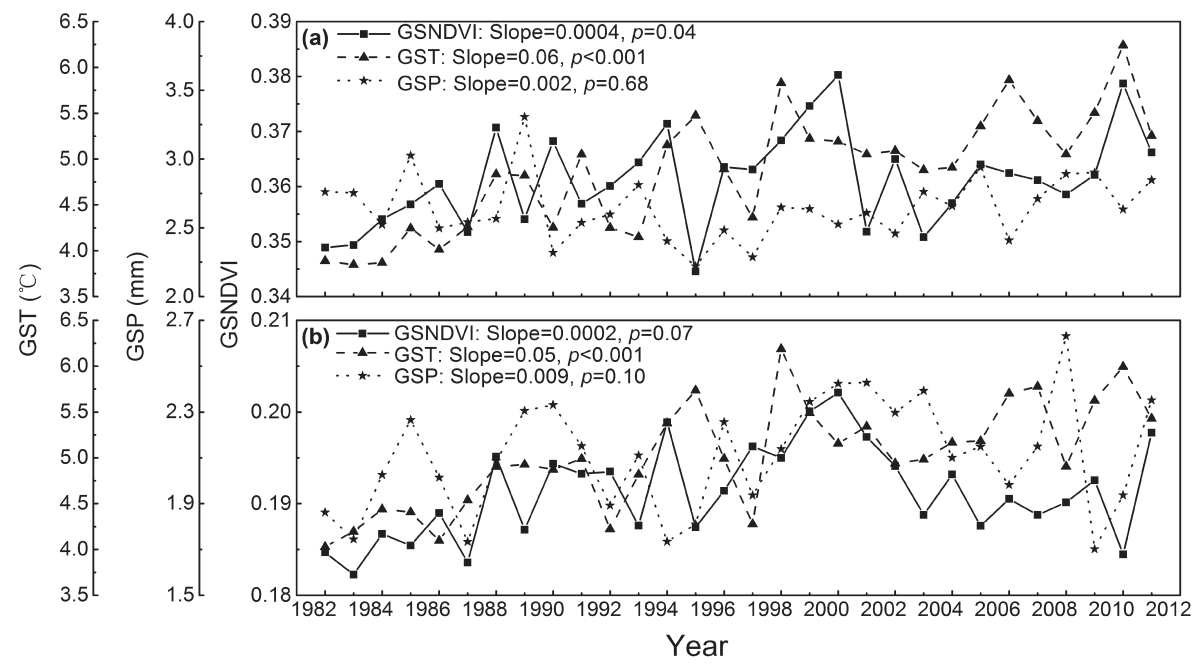

Figure 3. Interannual changes of GSNDVI, GST and GSP in Qinghai (a) and Xizang (b) Provinces from 1982 to 2011.

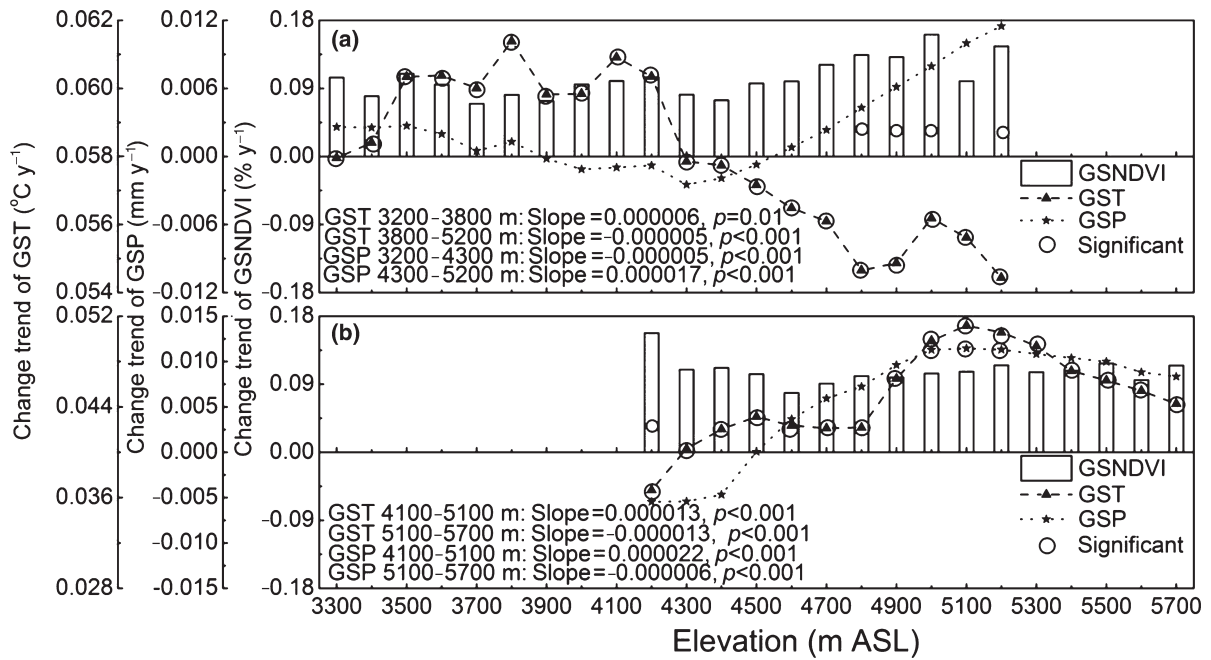

Figure 4. Change slopes of GSNDVI, GST and GSP at each elevation bin in Qinghai (a) and Xizang (b) Provinces. The white circle indicates that the change trend reached a statistically significant level $(p<0.05)$.

2006, the grassland GSNDVI followed a flat trend. During the study period, the grassland GSNDVI followed an increasing trend in the two provinces, which reached a statistically significant level in Qinghai Province. The change slopes of the grassland GST in Qinghai Province and Xizang Province were $0.06{ }^{\circ} \mathrm{C}$ year ${ }^{-1}$ and $0.05^{\circ} \mathrm{C}$ year $^{-1}$ with statistical significance $(p<0.001)$ during 1982-2011, respectively. No statistically significant GSP trends were observed in the two provinces.

The interannual fluctuations of the grassland GSNDVI and GSP showed different trends between Qinghai Province and Xizang Province (Figure 3). The grassland GSNDVI had larger values and increased faster in Qinghai Province (GSNDVI: 0.35-0.38, slope $=0.0004$ year $^{-1}$ ) than in Xizang Province (GSNDVI: 0.18-0.20, slope $=0.0002$ year $^{-1}$ ). The grassland GSP amount was also greater in Qinghai Province (GSP: 2.21-3.30 mm) than in Xizang Province (GSP: $1.70-2.63 \mathrm{~mm}$ ). In the entire studied period, the annual GSP reversed from decreasing (1982-1995: slope $=-0.02 \mathrm{~mm} \mathrm{year}^{-1}, p=$
$0.21, n=14)$ to increasing $(1995-2011:$ slope $=0.03 \mathrm{~mm}$ year $\left.^{-1}, p<0.01, n=17\right)$ in Qinghai Province, but shifted from increasing (1982-2001: slope $=0.02 \mathrm{~mm} \mathrm{year}^{-1}$, $p=0.05, n=20)$ to decreasing (2001-2011: slope $=$ $\left.-0.03 \mathrm{~mm}_{\text {year }}{ }^{-1}, p=0.33, n=11\right)$ in Xizang Province.

\subsection{Change trends of grassland GSNDVI, GST and GSP at different elevations}

The change percentages of the grassland GSNDVI were positive at all elevation bins in Qinghai and Xizang Provinces during the past 30 years (Figure 4). Although the change percentage values fell in the same range of $0.07-0.16 \%$ year $^{-1}$ in the two provinces, they had a greater variability among different elevation bins in Qinghai Province than in Xizang Province, especially below $4500 \mathrm{~m}$ ASL. In Qinghai Province, the change percentage exceeded $0.09 \%$ year $^{-1}$ in grasslands above $4500 \mathrm{~m}$ ASL and reached statistically significant level above $4700 \mathrm{~m}$ ASL. In Xizang Province, the change percentage exceeded 


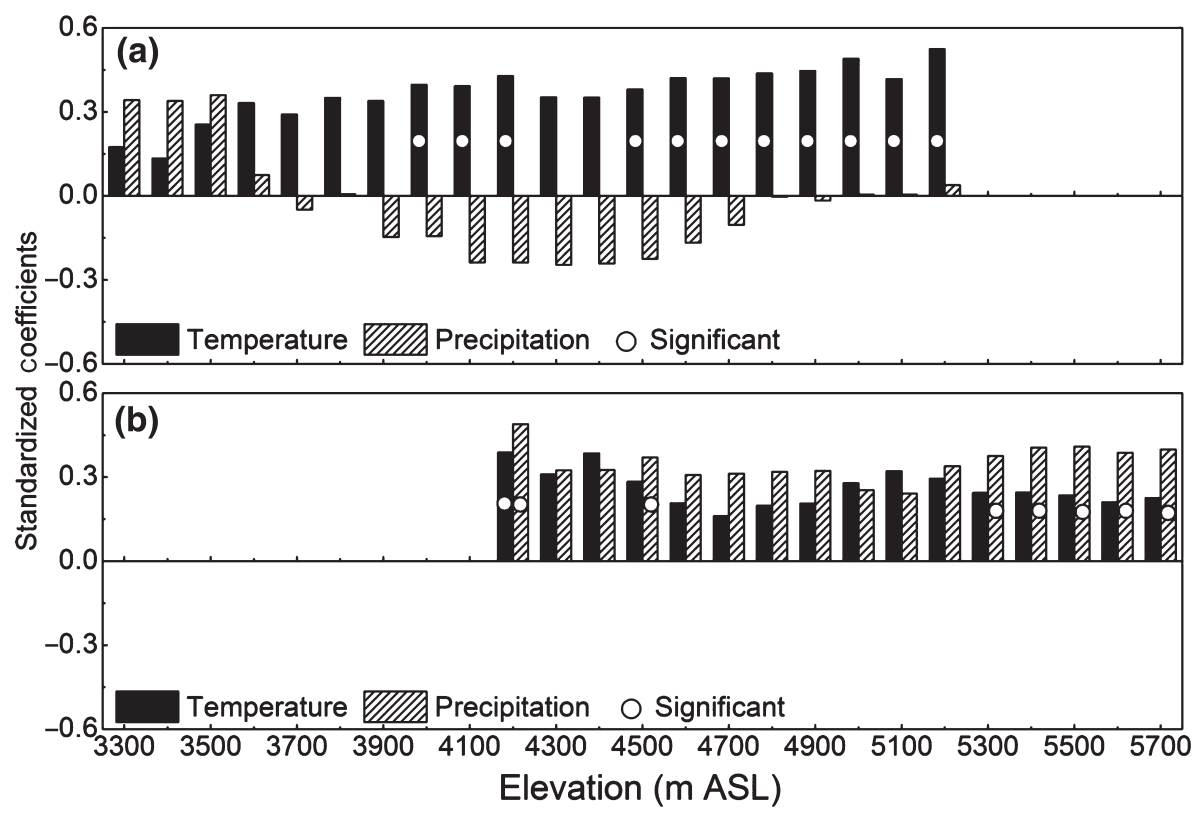

Figure 5. The standardized coefficients between GSNDVI and temperature and precipitation at each elevation bin in Qinghai (a) and Xizang (b) Provinces. The white circle dot means the correlation reached a statistically significant level $(p<0.05)$.

$0.09 \%$ year $^{-1}$ in the whole grasslands, except at the 4500-4600 m ASL bin.

The grassland GST underwent a more drastic increase in Qinghai Province (more than $0.05^{\circ} \mathrm{C}$ year ${ }^{-1}$ ) than in Xizang Province (between 0.04 and $0.05^{\circ} \mathrm{C}$ year ${ }^{-1}$ ) (Figure 4). The greatest warming trends occurred in grasslands between 3400 and $4200 \mathrm{~m}$ ASL in Qinghai Province with a rate around $0.06^{\circ} \mathrm{C}$ year ${ }^{-1}$. In Xizang Province, the GST warming trends were greater in grasslands above $4900 \mathrm{~m}$ ASL than in lower elevation grasslands. The grassland GSP showed enhanced wetting trends at higher elevations in both Qinghai and Xizang Provinces (Figure 4). The greatest wetting trends were detected above $4900 \mathrm{~m}$ ASL in the two provinces. The GSP wetting trends reached statistically significant levels in grasslands between 4900 and $5200 \mathrm{~m}$ ASL in Xizang Province. In contrast, the grassland GSP showed decreasing trends between 3800 and $4500 \mathrm{~m}$ ASL in Qinghai Province and below $4500 \mathrm{~m}$ ASL in Xizang Province, which are located in eastern Qinghai Province and southeastern Xizang Province, respectively.

\subsection{Climate change in relation to elevation}

The GST warming slopes changed faster in Xizang Province than in Qinghai Province along increasing elevations, though the warming slopes were larger in Qinghai Province than in Xizang Province (Figure 4). In Qinghai Province, the change trend of the warming slopes along increasing elevations shifted from increasing by $0.006{ }^{\circ} \mathrm{C}$ year $^{-1}$ per $1000 \mathrm{~m}$ elevation (3300-3800 $\mathrm{m} \mathrm{ASL)} \mathrm{to}$ decreasing by $-0.005^{\circ} \mathrm{C}$ year ${ }^{-1}$ per $1000 \mathrm{~m}$ elevation (3800-5200 m ASL). In Xizang Province, the change trend of the warming slopes along increasing elevations reversed from increasing by $0.013{ }^{\circ} \mathrm{C}_{\text {year }}{ }^{-1}$ per $1000 \mathrm{~m}$ elevation (4100-5100 $\mathrm{m}$ ASL) to decreasing by $-0.013^{\circ} \mathrm{C}$ year $^{-1}$ per $1000 \mathrm{~m}$ elevation (5100-5700 m ASL).

\subsection{Elevation-dependent climate sensitivities} of grassland vegetation variation

The relationships between grassland GSNDVI and climate factors exhibited different patterns between Qinghai Province and Xizang Province. In Qinghai Province, the standardized regression coefficients between grassland GSNDVI and GST were positive at all elevation bins, but the standardized regression coefficients between grassland GSNDVI and GSP were negative in grasslands between 3800 and $4700 \mathrm{~m}$ ASL (Figure 5(a)). The absolute values of the coefficients between GSNDVI and GST were larger than those between GSNDVI and GSP in grasslands above $3500 \mathrm{~m}$ ASL. In particular, the coefficients between GSNDVI and GST reached statistically significant levels in grasslands above $3900 \mathrm{~m}$ ASL except between 4200 and $4400 \mathrm{~m}$ ASL. In Xizang province, the standardized regression coefficients between grassland GSNDVI and GST and GSP were positive at all elevation bins, but the standardized regression coefficients between GSNDVI and GSP were greater than those between GSNDVI and GST (Figure 5(b)). The coefficients between GSNDVI and GSP were statistically significant in grasslands above $5200 \mathrm{~m}$ ASL.

\section{Discussion and conclusions}

4.1. Interannual change of grassland GSNDVI, GST and GSP

The change trends of grassland GSNDVI identified in this study were in accordance with previous studies during 1982-2006 (Piao et al., 2006b; Piao et al., 2011b). 
However, our finding of improved greenness under climate warming and wetting during 1982-2011 was inconsistent with previous findings of grassland degradation during 1982-2006 over the whole plateau (Piao et al., 2006a; Gao et al., 2010). The inconsistency could be caused by one segment of degraded greenness during 2000-2006 imbedded in the overall enhanced greenness trend during 1982-2011.

The findings of significant warming and nonsignificant precipitation trends as identified in this study across the plateau grasslands were in line with previous studies (Liu et al., 2009a). The GST values were within a similar range in the two provinces, and the GSP values were larger in Qinghai Province than in Xizang Province because of a longer rainy season fed by the East Asian monsoon than by the South Asian monsoon (Molnar et al., 2010), which accordingly nurtures denser grassland in Qinghai Province than in Xizang Province.

The spatial heterogeneous climate change found in the study is in accordance with prior regional-scale studies, such as faster warming in Qinghai Province than in Xizang Province (Yang et al., 2011a; Zhou and Ren, 2012; Yin et al., 2013), elevation-dependent wetting (Arakawa and Kitoh, 2012), and decreased GSP in the eastern and southeastern plateau (Feng and Zhou, 2012; Wang and Guo, 2012; Yang et al., 2014a). The more obvious climate warming in Qinghai Province than in Xizang province could be caused by two reasons: (1) a shrunk land and atmospheric energy budget over the plateau mainly caused by enhanced outgoing longwave radiation and weaker absorbed solar radiation (Duan and Wu, 2008; Yang et al., 2011b, 2014a; Wu et al., 2012). (2) Snow and glacier distributed at high elevation regions can slow down climate warming by reflecting solar radiation and consuming energy due to snow/ice melting (Yang et al., 2014a). The two above-mentioned effects might be more evident in Xizang Province due to a higher proportion of higher elevation region than in Qinghai province. An enhanced wetting along rising elevation might lie in that climate warming could accelerate glacier/snow thawing at high elevations, enhance local atmosphere moisture and consequently increase precipitation. Moreover, increased humidity and shrunk snow/ice would enhance income of downward long-wave radiation and absorption of solar radiation at high elevations (Rangwala et al., 2010), which results in more obvious elevation-dependent climate warming in Xizang Province. The decreased GSP in the eastern and southeastern plateau was mainly caused by the weakening Asian monsoon (Xu et al., 2006; Yang et al., 2014a).

\subsection{Change trends of grassland GSNDVI, GST and GSP at different elevations}

The plateau grassland gained improved greenness, but the variability of greenness gaining among different elevations was greater in Qinghai Province than in Xizang Province. This difference could be caused by two reasons: (1) Climate regime has more evident spatial gradients in Qinghai
Province than in Xizang Province. In Qinghai Province, climates cover wider temperature and precipitation ranges, with a temperate zone in the north and a sub-arctic zone in the south for temperature, and semi-humid/humid climate in the east and semi-arid/arid climate in the west for precipitation. In Xizang province, the temperature and precipitation ranges are relatively narrower, with most grassland distributed in the sub-arctic/arctic zone with semi-arid/arid climate. (2) The anthropogenic activity disturbances are more frequent in low elevation grasslands of Qinghai Province, where the population density is higher than in Xizang Province.

\subsection{Climate change in relation to elevation}

Previous studies addressing an elevation-dependent climate change pattern in the plateau mainly relied on ground meteorological records of CMA meteorological stations (Liu et al., 2009b; Rangwala et al., 2009). These stations are mainly distributed below $4200 \mathrm{~m}$ ASL. In this study, we used the interpolated continuous surface results and identified steeper GST warming slopes along increasing elevations in regions below $4200 \mathrm{~m}$ ASL. Such finding is consistent with previous finding using ground meteorological records.

\subsection{Elevation-dependent climate sensitivities of grassland vegetation}

The primary climate factors causing the grassland vegetation variations were different between Qinghai Province and Xizang Province. This finding is consistent with previous studies about impacts of climate change on grassland NPP over the plateau (Piao et al., 2006a; Gao et al., 2009; Fan et al., 2010; Piao et al., 2012). In Qinghai Province, temperature played a more important role in driving grassland growth than precipitation. In contrast, precipitation contributed a higher proportion than temperature in Xizang Province. This drastic contrast could be due to different climate sensitivity of grasslands between the two provinces. Different thermal heating systems and disparate water vapour sources form distinct climates between the two provinces (Yanai and Li, 1994; Yang et al., 2006, 2007a; Liu et al., 2008; Molnar et al., 2010). The different terrain and topography features further intensifies the climate differences between the two provinces (Chen et al., 2012; Wang and Guo, 2012; Yang et al., 2014a), which results in different grassland vegetation zones and a divergent climate sensitivity between the two provinces (Chang, 1983; Smith and Shi, 1992). This finding further implied the important role of geographic topography in driving local climate and ecosystem process, which also has been identified in Inner Mongolia Plateau in China (Dong et al., 2011).

The greater climate sensitivity of alpine grassland at higher elevations is related to the elevation-dependent gradients of ecosystem properties, such as plant element composition, species structure and soil microbial communities. At higher elevations, the alpine grassland can enrich foliar nitrogen element to strengthen photosynthetic 
capacity (Zhou et al., 2011; Zhou et al., 2013b; Zhou et al., 2013a). Along rising elevations, species diversity decreases and the proportion of endemic species increases (Vetaas and Grytnes, 2002; Wang et al., 2003; Klein et al., 2004; Li et al., 2014). At higher elevations, soil microbial communities can aggregate cold shock, nitrogen cycling and sulfur cycling genes to adapt cold environment ( $\mathrm{Fu}$ et al., 2012; Yang et al., 2013, 2014b), which set the stage for an enhanced capacity to cope with harsh environment for the higher elevation grasslands than the lower elevation grasslands. Furthermore, the elevation-dependent climate warming and wetting provide a more favourable condition for the plateau grassland at higher elevations, and the grassland consequently gained enhanced improvement along increasing elevations. On the other hand, the ever-increasing anthropogenic activities are playing an increasing role in driving vegetation variation in low elevation grasslands, which can confound our understanding on vegetation response to climate (Yu et al., 2012).

Previous related studies regarding the plateau vegetation response to climate change have been mostly based on time series datasets that were shorter than 30 years. This study employed a full 30-year climate and NDVI series data. To our knowledge, in the meantime, this study is the first by separating the plateau into two units (as separated by Tanggula Mountains) in evaluating vegetation's elevation-dependent sensitivities to climate change in the Qinghai-Xizang Plateau. The entire plateau grasslands experienced a significant warming in growing season during 1982-2011. However, the grassland vegetation features different climate sensitivities between the two geographic units, with temperature and precipitation being the main driving factor in Qinghai Province and Xizang Province, respectively. In particular, the high elevation grasslands in the plateau were characterized with higher climate sensitivity.

It should be pointed out that our results could still largely be affected by the qualities of the remote sensing data and the climate data interpolation method. The earlier version of the GIMMS NDVI dataset (i.e. 1982-2006) has been compared to differ from SPOT and MODIS NDVIs during 2001-2006 and can be biased in the western plateau (Dong et al., 2013; Zhang et al., 2013). Site-specific analysis based on field observations could further improve our understanding on the complicated relationship between climate change and alpine grassland variations in the future. Furthermore, our baseline map that defined grassland distribution was based on the land-cover data in 2000. It is highly likely that some grassland pixels might have changed into other land-cover types during our study period.

\section{Acknowledgements}

This research is supported by the 973 Programme (2013 CB956302) of the Ministry of Science and Technology of China, the China Postdoctoral Science Foundation
(2012 M510532, 2013 T60163), and One Hundred Talent Plan, Chinese Academy of Sciences.

\section{References}

Arakawa O, Kitoh A. 2012. Elevation dependency of summertime precipitation and its change by global warming over the Tibetan Plateau and the surroundings simulated by a $60-\mathrm{km}-\mathrm{mesh}$ atmospheric general circulation model. J. Meteorol. Soc. Jpn. Ser. II 90A: 151-165.

Beniston M, Diaz H, Bradley R. 1997. Climatic change at high elevation sites: an overview. Clim. Change 36: 233-251.

Boos WR, Emanuel KA. 2009. Annual intensification of the Somali jet in a quasi-equilibrium framework: observational composites. $Q$. J. R. Meteorol. Soc. 135: 319-335.

Bring J. 1994. How to standardize regression coefficients. J. Am. Stat. Assoc. 48: 209-213.

Chang DHS. 1981. The vegetation zonation of the Tibetan Plateau. Mt. Res. Dev. 1: 29-48.

Chang DHS. 1983. The Tibetan Plateau in relation to the vegetation of China. Ann. Mo. Bot. Gard. 70: 564-570.

Che M, Chen B, Innes JL, Wang G, Dou X, Zhou T, Zhang H, Yan J, Xu G, Zhao H. 2014. Spatial and temporal variations in the end date of the vegetation growing season throughout the Qinghai-Tibetan Plateau from 1982 to 2011. Agr. Forest. Meteorol. 189-190: 81-90.

Chen T, Yen M, Weng S. 2000. Interaction between the summer monsoons in East Asia and the South China Sea: intraseasonal monsoon modes. J. Atmos. Sci. 57: 1373-1392.

Chen B, Chao WC, Liu X. 2003. Enhanced climatic warming in the Tibetan Plateau due to doubling CO2: a model study. Clim. Dyn. 20: $401-413$.

Chen B, Xu X, Yang S, Zhang W. 2012. On the origin and destination of atmospheric moisture and air mass over the Tibetan Plateau. Theor. Appl. Climatol. 110: 423-435.

Chou C, Neelin JD, Su H. 2001. Ocean-atmosphere-land feedbacks in an idealized monsoon. Q. J. R. Meteorol. Soc. 127: 1869-1891.

Cong N, Wang T, Nan H, Ma Y, Wang X, Myneni RB, Piao S. 2013. Changes in satellite-derived spring vegetation green-up date and its linkage to climate in China from 1982 to 2010: a multimethod analysis. Glob. Change Biol. 19: 881-891.

Dong J, Liu J, Tao F, Xu X, Wang J. 2009. Spatio-temporal changes in annual accumulated temperature in China and the effects on cropping systems, 1980s to 2000. Clim. Res. 40: 37-48.

Dong J, Tao F, Zhang G. 2011. Trends and variation in vegetation greenness related to geographic controls in middle and eastern Inner Mongolia, China. Environ. Earth Sci. 62: 245-256.

Dong J, Zhang G, Zhang Y, Xiao X. 2013. Reply to Wang et al.: Snow cover and air temperature affect the rate of changes in spring phenology in the Tibetan Plateau. Proc. Natl. Acad. Sci. U.S.A. 110: E2856-E2857.

Duan AM, Wu GX. 2005. Role of the Tibetan Plateau thermal forcing in the summer climate patterns over subtropical Asia. Clim. Dyn. 24: $793-807$.

Duan A, Wu G. 2008. Weakening trend in the atmospheric heat source over the Tibetan Plateau during recent decades. Part I: Observations. J. Clim. 21: 3149-3164.

Fan J, Shao Q, Liu J, Wang J, Harris W, Chen Z, Zhong H, Xu X, Liu R. 2010. Assessment of effects of climate change and grazing activity on grassland yield in the Three Rivers Headwaters Region of Qinghai-Tibet Plateau, China. Environ. Monit. Assess. 170: 571-584.

Feng L, Zhou T. 2012. Water vapor transport for summer precipitation over the Tibetan Plateau: multidata set analysis. J. Geophys. Res-Atmos. 117: D20114.

Fensholt R, Proud SR. 2012. Evaluation of earth observation based global long term vegetation trends-intercomparing GIMMS and MODIS global NDVI time series. Remote Sens. Environ. 119: $131-147$.

Fensholt R, Rasmussen K, Nielsen TT, Mbow C. 2009. Evaluation of earth observation based long term vegetation trends-intercomparing NDVI time series trend analysis consistency of Sahel from AVHRR GIMMS, Terra MODIS and SPOT VGT data. Remote Sens. Environ. 113: $1886-1898$.

Frauenfeld OW, Zhang T, Serreze MC. 2005. Climate change and variability using European Centre for medium-range weather forecasts reanalysis (ERA-40) temperatures on the Tibetan Plateau. J. Geophys. Res-Atmos. 110: D02101. 
Fu R, Hu Y, Wright JS, Jiang J, Dickinson RE, Chen M, Filipiak M, Read WG, Waters JW, Wu D. 2006. Short circuit of water vapor and polluted air to the global stratosphere by convective transport over the Tibetan Plateau. Proc. Natl. Acad. Sci. U.S.A. 103: 5664-5669.

Fu G, Shen Z, Zhang X, Zhou Y. 2012. Response of soil microbial biomass to short-term experimental warming in alpine meadow on the Tibetan Plateau. Appl. Soil Ecol. 61: 158-160.

Gao Q, Li Y, Wan Y, Qin X, Jiangcun W, Liu Y. 2009. Dynamics of alpine grassland NPP and its response to climate change in Northern Tibet. Clim. Change 97: 515-528

Gao Q, Wan Y, Xu H, Li Y, Jiangcun W, Borjigidai A. 2010. Alpine grassland degradation index and its response to recent climate variability in Northern Tibet, China. Quatern. Int. 226: 143-150.

Gerten D, Schaphoff S, Haberlandt U, Lucht W, Sitch S. 2004. Terrestrial vegetation and water balance-hydrological evaluation of a dynamic global vegetation model. J. Hydrol. 286: 249-270

Giorgi F, Hurrell JW, Marinucci MR, Beniston M. 1997. Elevation dependency of the surface climate change signal: a model study. J. Clim. 10: 288-296.

Guo X, Yang K, Chen Y. 2011. Weakening sensible heat source over the Tibetan Plateau revisited: effects of the land-atmosphere thermal coupling. Theor. Appl. Climatol. 104: 1-12.

He H, McGinnis JW, Song Z, Yanai M. 1987. Onset of the Asian summer monsoon in 1979 and the effect of the Tibetan Plateau. Mon. Weather Rev. 115: 1966-1995.

Howard EE, Martha KR, Donald AW, Uma SB, Compton JT, Jorge EP. 2012. Dynamics of aboveground phytomass of the circumpolar Arctic tundra during the past three decades. Environ. Res. Lett. 7: 015506.

Hutchinson MF. 1995. Interpolating mean rainfall using thin plate smoothing splines. Int. J. Geogr. Inf. Syst. 9: 385-403.

Hutchinson MF, Dowling TI. 1991. A continental hydrological assessment of a new grid-based digital elevation model of Australia. Hydrol. Processes 5: 45-58.

Kang S, Xu Y, You Q, Fl gel W-A, Pepin N, Yao T. 2010. Review of climate and cryospheric change in the Tibetan Plateau. Environ. Res. Lett. 5: 015101.

Klein JA, Harte J, Zhao X. 2004. Experimental warming causes large and rapid species loss, dampened by simulated grazing, on the Tibetan Plateau. Ecol. Lett. 7: 1170-1179.

Li Y, Li D, Yang S, Liu C, Zhong A, Li Y. 2010. Characteristics of the precipitation over the eastern edge of the Tibetan Plateau. Meteorol. Atmos. Phys. 106: 49-56.

Li X, Gai J, Cai X, Li X, Christie P, Zhang F, Zhang J. 2014. Molecular diversity of arbuscular mycorrhizal fungi associated with two co-occurring perennial plant species on a Tibetan altitudinal gradient. Mycorrhiza 24: 95-107.

Liang X, Wang W. 1998. Associations between China monsoon rainfall and tropospheric jets. Q. J. R. Meteorol. Soc. 124: 2597-2623.

Liu X, Chen B. 2000. Climatic warming in the Tibetan Plateau during recent decades. Int. J. Climatol. 20: 1729-1742.

Liu J, Liu M, Tian H, Zhuang D, Zhang Z, Zhang W, Tang X, Deng X. 2005. Spatial and temporal patterns of China's cropland during 1990-2000: an analysis based on Landsat TM data. Remote Sens. Environ. 98: 442-456.

Liu X, Yin ZY, Shao X, Qin N. 2006. Temporal trends and variability of daily maximum and minimum, extreme temperature events, and growing season length over the eastern and central Tibetan Plateau during 1961-2003. J. Geophys. Res. 111: D19109.

Liu Z, Tian L, Yao T, Yu W. 2008. Seasonal deuterium excess in Nagqu precipitation: influence of moisture transport and recycling in the middle of Tibetan Plateau. Environ. Geol. 55: 1501-1506.

Liu J, Wang S, Yu S, Yang D, Zhang L. 2009a. Climate warming and growth of high-elevation inland lakes on the Tibetan Plateau. Global Planet. Change 67: 209-217.

Liu X, Cheng Z, Yan L, Yin Z. 2009b. Elevation dependency of recent and future minimum surface air temperature trends in the Tibetan Plateau and its surroundings. Global Planet. Change 68: 164-174.

Lu H, Wu N, Yang X, Shen C, Zhu L, Wang L, Li Q, Xu D, Tong G, Sun X. 2008. Spatial pattern of Abies and Picea surface pollen distribution along the elevation gradient in the Qinghai-Tibetan Plateau and Xinjiang, China. Boreas 37: 254-262.

Molnar P, Boos WR, Battisti DS. 2010. Orographic controls on climate and Paleoclimate of Asia: thermal and mechanical roles for the Tibetan Plateau. Annu. Rev. Earth Planet Sci. 38: 77-102.

Myneni RB, Keeling C, Tucker C, Asrar G, Nemani R. 1997. Increased plant growth in the northern high latitudes from 1981 to 1991. Nature 386: $698-702$.

Nemani RR, Keeling CD, Hashimoto H, Jolly WM, Piper SC, Tucker CJ, Myneni RB, Running SW. 2003. Climate-driven increases in global terrestrial net primary production from 1982 to 1999 . Science 300: 1560

Ni J, Herzschuh U. 2011. Simulating biome distribution on the Tibetan Plateau using a modified global vegetation model. Arct. Antarct. Alp. Res. 43: 429-441.

Parmesan C, Yohe G. 2003. A globally coherent fingerprint of climate change impacts across natural systems. Nature 421: $37-42$.

Pepin N, Lundquist J. 2008. Temperature trends at high elevations: patterns across the globe. Geophys. Res. Lett. 35: L14701.

Piao S, Fang J, He J. 2006a. Variations in vegetation net primary production in the Qinghai-Xizang Plateau, China, from 1982 to 1999. Clim. Change 74: 253-267.

Piao S, Mohammat A, Fang J, Cai Q, Feng J. 2006b. NDVI-based increase in growth of temperate grasslands and its responses to climate changes in China. Global Environ. Chang. 16: 340-348.

Piao S, Cui M, Chen A, Wang X, Ciais P, Liu J, Tang Y. 2011a. Altitude and temperature dependence of change in the spring vegetation green-up date from 1982 to 2006 in the Qinghai-Xizang Plateau. Agr. Forest. Meteorol. 151: 1599-1608.

Piao S, Wang X, Ciais P, Zhu B, Wang T, Liu J. 2011b. Changes in satellite-derived vegetation growth trend in temperate and boreal Eurasia from 1982 to 2006. Glob. Change Biol. 17: 3228-3239.

Piao S, Tan K, Nan H, Ciais P, Fang J, Wang T, Vuichard N, Zhu B. 2012. Impacts of climate and $\mathrm{CO}_{2}$ changes on the vegetation growth and carbon balance of Qinghai-Tibetan grasslands over the past five decades. Global Planet. Change 98-99: 73-80.

Privé NC, Plumb RA. 2007. Monsoon dynamics with interactive forcing. Part II: impact of eddies and asymmetric geometries. J. Atmos. Sci. 64: $1431-1442$.

Qin J, Yang K, Liang S, Guo X. 2009. The altitudinal dependence of recent rapid warming over the Tibetan Plateau. Clim. Change 97: $321-327$.

Rangwala I, Miller JR. 2012. Climate change in mountains: a review of elevation-dependent warming and its possible causes. Clim. Change 114: 527-547.

Rangwala I, Miller JR, Xu M. 2009. Warming in the Tibetan Plateau: possible influences of the changes in surface water vapor. Geophys. Res. Lett. 36: L06703.

Rangwala I, Miller J, Russell G, Xu M. 2010. Using a global climate model to evaluate the influences of water vapor, snow cover and atmospheric aerosol on warming in the Tibetan Plateau during the twenty-first century. Clim. Dynam. 34: 859-872.

Shen M, Tang Y, Chen J, Zhu X, Zheng Y. 2011. Influences of temperature and precipitation before the growing season on spring phenology in grasslands of the central and eastern Qinghai-Tibetan Plateau. Agr Forest. Meteorol. 151: 1711-1722.

Shen M, Zhang G, Cong N, Wang S, Kong W, Piao S. 2014. Increasing altitudinal gradient of spring vegetation phenology during the last decade on the Qinghai-Tibetan Plateau. Agr. Forest. Meteorol. 189-190: $71-80$

Simmonds I, Bi D, Hope P. 1999. Atmospheric water vapor flux and its association with rainfall over China in Summer. J. Clim. 12: $1353-1367$.

Smith EA, Shi L. 1992. Surface forcing of the infrared cooling profile over the Tibetan Plateau. Part I: influence of relative longwave radiative heating at high altitude. J. Atmos. Sci. 49: 805-822.

Tao J, Zhang Y, Yuan X, Wang J, Zhang X. 2013a. Analysis of forest fires in Northeast China from 2003 to 2011. Int. J. Remote Sens. 34 $8235-8251$.

Tao J, Zhang Y, Zhu J, Jiang Y, Zhang X, Zhang T, Xi Y. 2013b. Elevation-dependent temperature change in the Qinghai-Xizang Plateau grassland during the past decade. Theor. Appl. Climatol., DOI: 10.1007/s00704-013-0976-Z.

Tucker CJ, Pinzon JE, Brown ME, Slayback DA, Pak EW, Mahoney R, Vermote EF, El Saleous N. 2005. An extended AVHRR 8-km NDVI dataset compatible with MODIS and SPOT vegetation NDVI data. Int. J. Remote Sens. 26: 4485-4498.

Vetaas OR, Grytnes JA. 2002. Distribution of vascular plant species richness and endemic richness along the Himalayan elevation gradient in Nepal. Global Ecol. Biogeogr. 11: 291-301.

Walther GR, Post E, Convey P, Menzel A, Parmesan C, Beebee TJC, Fromentin JM, Hoegh-Guldberg O, Bairlein F. 2002. Ecological responses to recent climate change. Nature 416: 389-395.

Wang B, Fan Z. 1999. Choice of South Asian summer monsoon indices. Bull. Am. Meteorol. Soc. 80: 629-638.

Wang C, Guo Y. 2012. Precipitable water conversion rates over the Qinghai-Xizang (Tibet) Plateau: changing characteristics with global warming. Hydrol. Processes 26: 1509-1516. 
Wang G, Zhou G, Yang L, Li Z. 2003. Distribution, species diversity and life-form spectra of plant communities along an altitudinal gradient in the northern slopes of Qilianshan Mountains, Gansu, China. Plant Ecol. 165: 169-181.

Wang C, Long R, Wang Q, Ding L, Wang M. 2007. Effects of altitude on plant-species diversity and productivity in an alpine meadow, Qinghai-Tibetan plateau. Aust. J. Bot. 55: 110-117.

Wu G, Liu Y, Zhang Q, Duan A, Wang T, Wan R, Liu X, Li W, Wang Z, Liang X. 2007. The influence of mechanical and thermal forcing by the Tibetan Plateau on Asian climate. J. Hydrometeorol. 8: 770-789.

Wu G, Liu Y, He B, Bao Q, Duan A, Jin F. 2012. Thermal controls on the Asian summer monsoon. Sci. Rep. 2: 1-7.

Xie S, Xu H, Saji NH, Wang Y, Liu W. 2006. Role of narrow mountains in large-scale organization of Asian Monsoon convection. J. Clim. 19: 3420-3429.

Xu M, Chang C, Fu C, Qi Y, Robock A, Robinson D, Zhang H 2006. Steady decline of east Asian monsoon winds, 1969-2000: evidence from direct ground measurements of wind speed. J. Geophys. Res-Atmos. 111: D24111.

Xu X, Shi X, Wang Y, Peng S, Shi X. 2008. Data analysis and numerical simulation of moisture source and transport associated with summer precipitation in the Yangtze River Valley over China. Meteorol. Atmos. Phys. 100: 217-231.

Yanai M, Li C. 1994. Mechanism of heating and the boundary layer over the Tibetan Plateau. Mon. Weather Rev. 122: 305-323.

Yang Y, Piao S. 2006. Variations in grassland vegetation cover in relation to climatic factors on the Tibetan Plateau. Chinese J. Plant Ecol. 30 $1-8$

Yang M, Yao T, Wang H, Tian L, Gou X. 2006. Estimating the criterion for determining water vapour sources of summer precipitation on the northern Tibetan Plateau. Hydrol. Processes 20: 505-513.

Yang M, Yao T, Gou X, Wang H, Hao L. 2007a. Comparison analysis of the summer monsoon precipitation between northern and southern slopes of Tanggula Mountains, Qinghai-Xizang (Tibetan) Plateau: a case study in summer 1998. Hydrol. Processes 21: 1841-1847.

Yang M, Yao T, Gou X, Wang H, Tang H. 2007b. The spatially heterogeneous distribution of precipitation of the Anduo area, Tibetan Plateau, in summer 1998. Hydrolog. Sci. J. 52: 645-653.

Yang Y, Fang J, Tang Y, Ji C, Zheng C, He J, Zhu B. 2008. Storage, patterns and controls of soil organic carbon in the Tibetan grasslands. Glob. Change Biol. 14: 1592-1599.

Yang K, Guo X, He J, Qin J, Koike T. 2011a. On the climatology and trend of the atmospheric heat source over the Tibetan Plateau: an experiments-supported revisit. J. Clim. 24: 1525-1541.

Yang K, Ye B, Zhou D, Wu B, Foken T, Qin J, Zhou Z. 2011b. Response of hydrological cycle to recent climate changes in the Tibetan Plateau. Clim. Change 109: 517-534.

Yang Y, Wu L, Lin Q, Yuan M, Xu D, Yu H, Hu Y, Duan J, Li X, He Z, Xue K, van Nostrand J, Wang S, Zhou J. 2013. Responses of the functional structure of soil microbial community to livestock grazing in the Tibetan alpine grassland. Glob. Change Biol. 19: 637-648.

Yang K, Wu H, Qin J, Lin C, Tang W, Chen Y. 2014a. Recent climate changes over the Tibetan Plateau and their impacts on energy and water cycle: a review. Global Planet. Change 112: 79-91.

Yang Y, Gao Y, Wang S, Xu D, Yu H, Wu L, Lin Q, Hu Y, Li X, He Z, Deng Y, Zhou J. 2014b. The microbial gene diversity along an elevation gradient of the Tibetan grassland. ISME J. 8: 430-440.
Yin Y, Wu S, Zhao D, Zheng D, Pan T. 2013. Modeled effects of climate change on actual evapotranspiration in different eco-geographical regions in the Tibetan Plateau. J. Geophys. Res. 23: 195-207.

You Q, Kang S, Aguilar E, Yan Y. 2008. Changes in daily climate extremes in the eastern and central Tibetan Plateau during 1961-2005. J. Geophys. Res-Atmos. 113: D07101.

You Q, Kang S, Pepin N, Flügel WA, Yan Y, Behrawan H, Huang J. 2010. Relationship between temperature trend magnitude, elevation and mean temperature in the Tibetan Plateau from homogenized surface stations and reanalysis data. Global Planet. Change 71: $124-133$

Yu C, Zhang Y, Claus H, Zeng R, Zhang X, Wang J. 2012. Ecological and environmental issues faced by a developing Tibet. Environ. Sci. Technol. 46: 1979-1980.

Zhang X, Liu J, Tian L, He Y, Yao T. 2004. Variations of $\delta^{18} \mathrm{O}$ in precipitation along vapor transport paths. Adv. Atmos. Sci. 21: $562-572$.

Zhang G, Zhang Y, Dong J, Xiao X. 2013. Green-up dates in the Tibetan Plateau have continuously advanced from 1982 to 2011. Proc. Natl. Acad. Sci. U.S.A. 110: 4309-4314.

Zhao P, Chen L. 2001. Climatic features of atmospheric heat source/sink over the Qinghai-Xizang Plateau in 35 years and its relation to rainfall in China. Sci. China Ser. D 44: 858-864.

Zhong L, Ma Y, Salama MS, Su Z. 2010. Assessment of vegetation dynamics and their response to variations in precipitation and temperature in the Tibetan Plateau. Clim. Change 103: 519-535.

Zhou Y, Ren G. 2012. Change in extreme temperature event frequency over mainland China, 1961-2008. Clim. Res. 50: 125-139.

Zhou L, Tucker CJ, Kaufmann RK, Slayback D, Shabanov NV, Myneni RB. 2001. Variations in northern vegetation activity inferred from satellite data of vegetation index during 1981 to 1999. J. Geophys. Res-Atmos. 106: 20069-20083.

Zhou Y, Fan J, Zhang W, Harris W, Zhong H, Hu Z, Song L. 2011. Factors influencing altitudinal patterns of $\mathrm{C}_{3}$ plant foliar carbon isotope composition of grasslands on the Qinghai-Tibet Plateau. China. Alp. Bot. 121: 79-90.

Zhou Y, Fan J, Harris W, Zhong H, Zhang W, Cheng X. 2013a. Relationships between $\mathrm{C}_{3}$ plant foliar carbon isotope composition and element contents of grassland species at high altitudes on the Qinghai-Tibet Plateau, China. PLoS One 8: e60794.

Zhou Y, Fan J, Zhong H, Zhang W. 2013b. Relationships between altitudinal gradient and plant carbon isotope composition of grassland communities on the Qinghai-Tibet Plateau, China. Sci. China Ser. D 56: $311-320$.

Zhu X, Liu Y, Wu G. 2012. An assessment of summer sensible heat flux on the Tibetan Plateau from eight data sets. Sci. China Ser. D 55: $779-786$.

Zhu Z, Bi J, Pan Y, Ganguly S, Anav A, Xu L, Samanta A, Piao S, Nemani R, Myneni R. 2013. Global data sets of vegetation leaf area index (LAI) $3 \mathrm{~g}$ and fraction of photosynthetically active radiation (FPAR) $3 \mathrm{~g}$ derived from global inventory modeling and mapping studies (GIMMS) normalized difference vegetation index (NDVI3g) for the period 1981 to 2011. Remote Sens. 5: 927-948.

Zuo Z, Zhang R, Zhao P. 2011. The relation of vegetation over the Tibetan Plateau to rainfall in China during the boreal summer. Clim. Dyn. 36: 1207-1219. 